\title{
The Relationship Between Industrial Structure and Economic Growth in China- An Empirical Study Based on Panel Data
}

\author{
Yunxin $\mathrm{Yi}^{1}{ }^{1 *}$ \\ ${ }^{1}$ The University of Melbourne, Faculty of Business and Economics, Melbourne, Victoria, Australia
}

\begin{abstract}
Industrial structure plays a vital role in social and economic progress, as well as the core in the domain of industrial economics. This paper reviewed the coordination of industrial structure and employment rate in primary, secondary, and tertiary industry, respectively by looking at its coordination coefficient. More importantly, this paper examined the relationship between industrial structure and economic growth using panel data from 2011 to 2019 and constructing a GMM model to measure the effects. Our findings indicate that the acceleration in economic growth, to a large extent, can be credited to an enhanced contribution from the service sector.
\end{abstract}

\section{Introduction}

Industrial structure has always been a distinguished clue for sophisticated social and economic phenomena. In the new round of economic transformation, the constant adjustment and optimization of industrial structure are also expected to reinvigorate the economy in regions, across countries, and eventually at the global level. In the process of injecting new energy into economic development, changes in industrial structure not only are conducive to the reallocation of available resources, but also ensure the coordinated development of industrial development and fundamental needs originated from the country's reality.

China has gone through an extraordinary economic transformation from a single-product, heavy-industry economy to a diverse and vibrant economy that has great potential to grow and prosper. After the reform and opening-up policy in 1978, China has instigated a series of industrial restructuring to ensure the stable operation of the macro economy, including the strong support for light industry, the new normal of economic development, and the most recent structural reform on the supply side. However, over the past two decades, China has experienced a slowdown in annual GDP growth rate, which is below $8 \%$ for consecutive eight years [1]. According to the objective economic laws and experience from other countries, an emerging economy is faced with challenges of the upgrading of industrial structure, which also provides an opportunity to get rid of the middleincome trap and gain competitive edges in international competition.

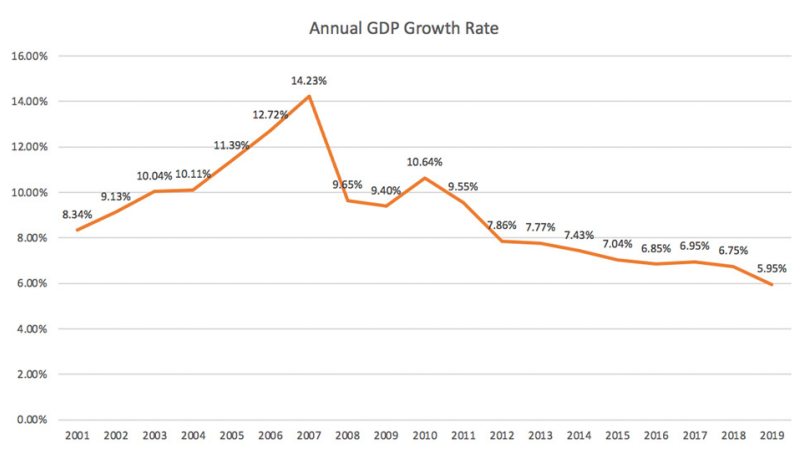

Fig. 1. Annual GDP growth rate

The existing body of research, home and abroad, has suggested that a rational and balanced industrial structure can greatly promote economic growth, whereas too much emphasis on the service industry without sufficient supporting evidence might encumber the economy in the long run. On the basis of previous literature, this paper intends to investigate how industrial structure and the process of structural transformation affect economic growth in China. Another purpose is to find out the benign integrations between industrial structure and economic development while driving high-quality growth. This paper first gives a brief overview of the evolution of industrial structure in China. It will then go on to use cross-provincial panel data to quantitatively analyze the relationship between industrial structure and economic growth in 31 provinces and cities. In closing, several suggestions are proposed to spur the continuous increasing of China's economy.

\footnotetext{
* Corresponding author : junxiny@student.unimelb.edu.au
} 


\section{Industrial Structure in China}

It has been widely acknowledged that various industries could provide a vast majority of products and services that people will need and use in their daily living [2]. During this process, a broad range of economic products have been produced, transported, priced, and traded, and eventually become a critical part of both the macroeconomic circulation and the micro economic function. To meet the flexible and diverse needs of statistics and measurement, government agencies around the world generally prescribe the structure of industry based on the sequential order of social productive activities or the value being created to prime resources.

\subsection{Classification of Three Sectors}

The industrial structure stands for the main composition of a country's social economic production, and can be divided into the primary industry, secondary industry, and tertiary industry. They can also be referred to as the agricultural, manufacturing, and services sector. The dividing standards for these three concepts may vary in different countries and regions, and this paper mainly focuses on the most commonly used classification in China. According to the latest version of National Economical Industrial Classification (GB/T4754-2002), primary industry, also described as agricultural sector, is the fundamental industry connected with extracting or gathering raw materials, and this category includes agriculture, forestry, hunting, fishing, mining, and oil and gas exploitation [3]. Secondary industry is also known as manufacturing for it is concerned with processing raw materials into practical products [4]. This kind of economic activity involves construction, electricity supply, energy utilities, manufacturing and recycling, and other intermediate industries. The tertiary industry emphasizes all kinds of services that support the primary and secondary industry, along with any other economic activities that have not been covered. These services might contain transport, real estate, financial intermediaries, education, hotel and restaurant, and other community and personal services.

\subsection{Rationality of Industrial Structure}

A country's industrial structure and the proportion of each section are never fixed. It constantly evolved with the development trends of three divisions, the overall state of national economy, and the changing needs of communities and individuals. The central government also adopts a series of reform policies to optimize and upgrade the industrial system, to minimize the regional economic disparities, and to achieve sustainable and coordinated future development.

Therefore, this paper first explores the rationality behind the industrial structure, which means that within the comprehensive industry framework, primary, secondary, and tertiary industry are in the state of harmonious adjustment or interaction under certain prerequisites [5]. From the perspective of classic economic theory, the general industrial structure can be in the optimal status when resources are efficiently allocated and each sector organically interacts with each other. To make the results comparable and analyzable between different years, this paper introduced the discrete ratio of the structure to quantitatively measure the rationality of industrial structure in reference to previous literature.

The discrete ratio of structure is an extensively used economic metric to investigate the degree of symmetry between the output value structure of three industries and the employment structure [6]. It is derived by calculating the percentage of the economic contributions to GDP of each industry and its employment figures, and then subtracted the ratio of 1 to determine the degree of deviation. The formula can be written as:

$$
S_{i}=\frac{Y_{i} / Y}{E_{i} / E}-1
$$

In formula (1), Si stands for the discrete ratio of structure of the industry $i$ in different years, and $i$ is used to denote either primary, secondary, or tertiary industry. $Y$ represents the gross domestic product (GDP), and similarly, $Y i$ represents the output production value of the industry $i$. $E$ means the total employment, and $E i$ means the employment figure of the industry $i$. When $\mathrm{S}$ is zero, the output value of industry equals the total employment, which indicates that the industrial structure has reached the state of equilibrium. However, if $\mathrm{S}$ does not equal to zero or its absolute value is relatively large, there is a certain amount of deviation or the industrial structure rather unreasonable.

\subsection{Analysis of Industrial Structure}

Table 1 presents the discrete ratio of industrial structure in primary, secondary, and tertiary industry based on cross-sectional time-series data from 2001 to 2020 . Figure 1 further shows the overall trend and some main characteristics of this indicator. For primary industry, the discrete ratio of industrial structure is always negative, ranging from -0.937 to -0.829 . This fact reveals that the proportion of those employed in the primary industry has been much higher than its output value, and there exists a large number of agricultural surplus labor forces. A major reason might be that the primary industry has a relatively low threshold to employment, but their production output did not rise as expected, indicating that the labor forces being absorbed are mismatched.

Table 1. Ratio of industrial structure of each industry

\begin{tabular}{|c|c|c|c|}
\hline Year & $\begin{array}{c}\text { Primary } \\
\text { Industry }\end{array}$ & $\begin{array}{c}\text { Secondary } \\
\text { Industry }\end{array}$ & $\begin{array}{c}\text { Tertiary } \\
\text { Industry }\end{array}$ \\
\hline 2001 & -0.908 & 1.081 & 0.769 \\
\hline 2002 & -0.918 & 1.308 & 0.626 \\
\hline 2003 & -0.937 & 1.681 & 0.331 \\
\hline 2004 & -0.844 & 1.302 & 0.333 \\
\hline 2005 & -0.884 & 1.122 & 0.411 \\
\hline
\end{tabular}




\begin{tabular}{|l|l|l|l|}
\hline 2006 & -0.897 & 0.972 & 0.425 \\
\hline 2007 & -0.934 & 0.869 & 0.460 \\
\hline 2008 & -0.869 & 0.787 & 0.392 \\
\hline 2009 & -0.895 & 0.881 & 0.282 \\
\hline 2010 & -0.902 & 1.000 & 0.127 \\
\hline 2011 & -0.882 & 0.763 & 0.230 \\
\hline 2012 & -0.851 & 0.650 & 0.247 \\
\hline 2013 & -0.866 & 0.611 & 0.226 \\
\hline 2014 & -0.847 & 0.525 & 0.229 \\
\hline 2015 & -0.845 & 0.355 & 0.318 \\
\hline 2016 & -0.856 & 0.250 & 0.379 \\
\hline 2017 & -0.829 & 0.217 & 0.360 \\
\hline 2018 & -0.843 & 0.248 & 0.328 \\
\hline 2019 & -0.845 & 0.185 & 0.340 \\
\hline
\end{tabular}

By comparison, the discrete ratios of secondary industry and tertiary industry have positive value and greater fluctuations over time. The secondary industry has the highest degree of distribution in a range between 1.000 and 1.081. This phenomenon shows that there is insufficient use of its total employment and underutilization of the labor force. But it can be seen from the general trend that the indicator is closer to zero in recent years, which means that it gradually absorbs the growth of the labor force. On the other hand, the tertiary industry can be regarded to have the best ratio of structure, for it has low volatility and is stabilized near a value of zero. Starting from 2016, the discrete ratio of structure in tertiary industry is a bit above those in secondary industry, which leaves some room for tertiary industry to fully absorb the rest of the labor force.

Overall, the industrial structure in China did not change much in the twentieth century and has formed a "231" situation [7]. The primary industry owns the largest number of the total employment, but makes the least economic contribution to GDP. On the contrary, second and tertiary industry have a comparatively balanced level of output value and employment structure, occupying a small proportion of the labor force. There might be a discrepancy among the three divisions suggests from overall dimensions in the macro-level. Correspondingly, in order to maintain fast yet steady economic growth, it is noted that China is adjusting the national industry structure by shifting its focus on the tertiary industry and forging a new pattern of " 321 ", which is recognized as an ideal economic structure in the world.

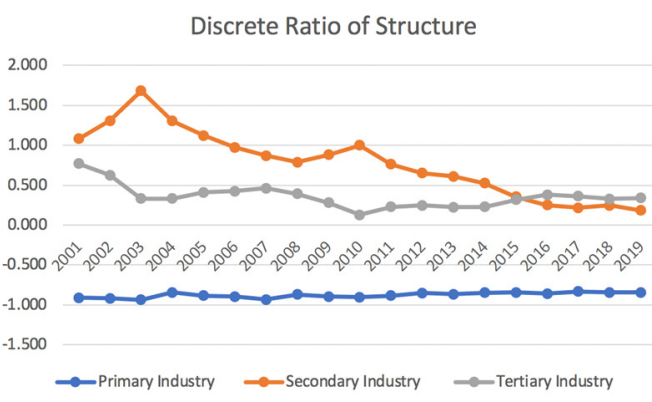

Fig. 2. Discrete ratio of structure

\section{Empirical Analysis: Industrial Structure and Economic Growth}

To delve deep into academic discussions concerning the relationship between industrial structure and economic growth, this paper collected panel data of all 31 provinces and municipalities in China from 2011 to 2019 and performed data analysis using STATA software package to examine the effects of primary, secondary, and tertiary industry on economic growth. This section also includes the process of selecting variables, building an empirical model using the Generalized Method of Moments (GMM), and amazing the results of multiple regression.

\subsection{Data Availability}

Panel data, often referred to as longitudinal data, contain both cross-sectional components and times series components, and reflect the differences observed between various subjects and the changes over time [8]. This type of dataset allows academic researchers to analyze a vast amount of unique data points and to examine variables and relationships more accurately than a single crosssectional or time-series data. Since the industrial and economic structures vary greatly in different places and time, it would be necessary to improve the efficiency of econometrics estimates through panel data analysis, combining the inter-regional differences and continuoustime dynamics [9].

The panel data of 31 provinces and cities in China from 2011 to 2019 was retrieved from the National Bureau of China, China Statistical Yearbook over the same period, and Wind Database. To find out the linkage between three sectors and economic development, this paper selected the national and provincial GDP in primary, secondary, and tertiary industry, respectively. GDP is known as a comprehensive indicator of a country's economic activities and measures the total value of both finished goods and services produced in one country [10]. The summary of descriptive statistics of sample variables is listed below in Table 2 .

Table 2. Descriptive statistics

\begin{tabular}{|c|c|c|c|c|}
\hline & $\begin{array}{c}\text { Total } \\
\text { GDP }\end{array}$ & $\begin{array}{c}\text { Primary } \\
\text { Industry }\end{array}$ & $\begin{array}{c}\text { Secondary } \\
\text { Industry }\end{array}$ & $\begin{array}{c}\text { Tertiary } \\
\text { Industry }\end{array}$ \\
\hline Mean & 31687.8 & 2273.3 & 12309.4 & 17105.1 \\
\hline SE & 4642.6 & 275.7 & 1993.2 & 2540.8 \\
\hline
\end{tabular}




\begin{tabular}{|c|c|c|c|c|}
\hline Median & 24667.3 & 2086.7 & 9392.0 & 12125.7 \\
\hline SD & 25848.7 & 1534.9 & 11097.7 & 14146.8 \\
\hline Kurtosis & 2.2 & -1.0 & 2.3 & 2.1 \\
\hline Skewness & 1.5 & 0.2 & 1.6 & 1.4 \\
\hline Range & 106289.1 & 5009.9 & 42871.9 & 59344.1 \\
\hline Minimum & 1697.8 & 107.1 & 635.6 & 924.0 \\
\hline Maximum & 107986.9 & 5117.0 & 43507.5 & 60268.1 \\
\hline Sum & 982320.5 & 70473.8 & 381590.2 & 530256.7 \\
\hline Count & 31.0 & 31.0 & 31.0 & 31.0 \\
\hline
\end{tabular}

Figure 2 describes the distribution of industry in different regions in 2019. When it comes to the economic distribution for each industry, nearly all the provinces and cities manifest a typical structure of " 321 ". This trend also points out that the tertiary industry continues to be the mainstay industry and will be further supported and encouraged by local government.

Distribution of three industries in 31 provinces and cities in 2019

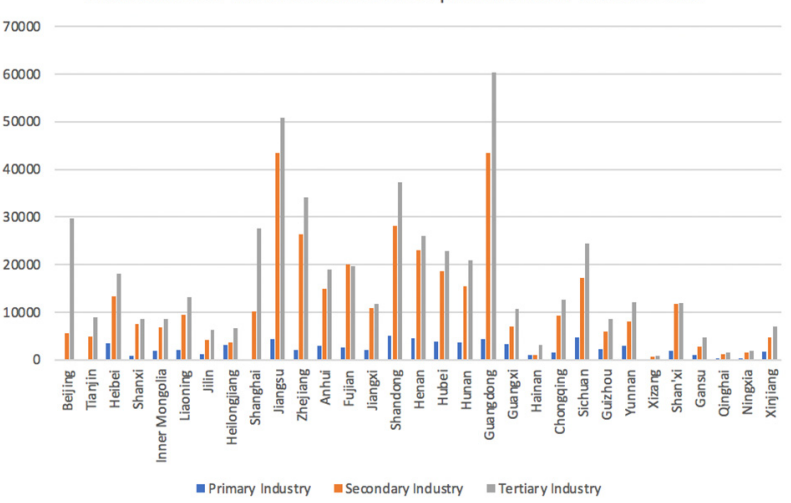

Fig. 3. Distribution of three industries in 2019

\subsection{Model Building}

In order to investigate the correlation between industrial structure and economic growth, this paper built a dynamic panel-data model and introduced the lagged response variables to the static model to display the hysteresis effect, written in (2).

$$
\begin{gathered}
Y_{i t}=\alpha+\rho_{1} y_{i, t-1}+\rho_{2} y_{i, t-2}+\rho_{3} r f_{i, t-1}+ \\
\rho_{4} r s_{i, t-1}+\rho_{5} r t_{i, t-1}+u_{i}+\varepsilon_{i t}
\end{gathered}
$$

where $Y_{i t}$ represents the output value of GDP in province/city $i$ and in the based year $t$, and by that analogy, $Y_{i, t-1}$ represents the output value of GDP in province/city $i$ during the year before year $t . u_{i}$ stands for the entity fixed effects, and $\varepsilon_{i t}$ is a random perturbed variable. To ensure the dynamic panel data model is robust and its meanings on China's provincial panel data are reliable, the model that $\varepsilon_{i t}$ does not have autocorrelation, and $\left|\Delta y_{i, t-1}, \Delta y_{i, t-2}, \ldots\right|$ is not related to $u_{i}$.

It is also noted that this paper selects the generalized methods of moments (GMM) estimation rather than a simple linear regression. GMM describes a statistical method that forecasts the value of unknown parameters by observing retrieved economic datasets [11]. A major advantage of GMM is that it does not require statistical hypotheses about the distribution of underlying parameters [11]. In this study, since GDP growth has strong time continuity, that is to say, the GDP growth rate in the first sub-period and second sub-period may still have an impact on the GDP growth rate in current time, Ordinary Least Squares (OLS) regression analysis is applicable to this model and may lead to significant deviations. Therefore, using the GMM model could increase the accuracy of estimation and achieve credible results.

\subsection{Result Analysis}

The results of dynamic penal-data estimation are presented in Figure 3. This paper conducted a thorough analysis of panel data retrieve from 31 provinces and cities in China ranging from 2011 to 2019. We calculated how much the added value in primary, secondary, and tertiary industry weigh in overall GDP growth, denoted by $r f, r s$, and $r t$, respectively. On the basis of controlling the economic growth rate in year $i-1$, year $i-2$, as represented in $L 1 . d g d p$ and $L 2 . d g d p$, and the output value of GDP in the year $i$ as Li.gdp, this paper imported the calculated proportions of three industries in the systematic GMM model.

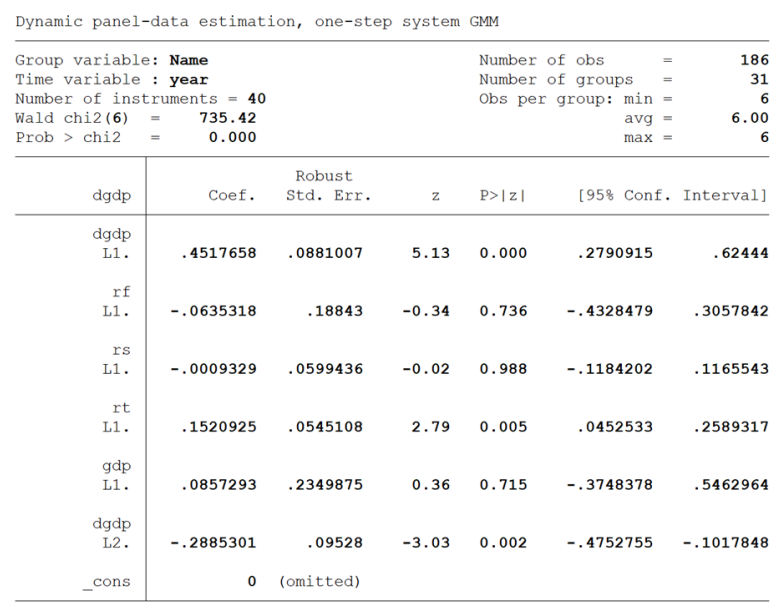

Fig. 4. GMM results

The GMM results further enhanced our understanding of the relationship between industrial structure and economic growth. Our findings imply that economic contributions from the primary and secondary industry at year $i$ have no significant impact on GDP growth, with the interrelated coefficient of -0.06 and -0.00 respectively. However, the effects of tertiary industry on the economic development are notably positive and statistically significant, with every percent increase of its output production value in year $i-1$, the overall GDP will rise by 1.15 percentage two years later in the year $i$. Therefore, by comparison, the service industry has the greatest influence on provincial and national economic growth. We can also conclude that energetically developing the tertiary industry is very likely to boost economic growth and bolster the country's long-term prosperity. 
Meanwhile, this paper carried out several tests to verify the credibility of our results, as summarized in Table 3. The test results of GMM show that the $p$ value of the AR test is 0.793 and the p value of the Hansen test is 1 , both greater than 0.1 and meet the criteria of using the GMM model. That is to say, the empirical results in this study have been validated and our findings can be considered reliable for the research field.

\section{Conclusion}

The aim of the present research was to summarize the overall trend and evolutionary process of industrial structure in China, and to examine the relationship between industrial structure and economic growth. By looking at the discrete ratio of structure, this paper finds out that, in the past couple of years, China has maintained a "231" situation, and compared with primary industry, second and tertiary industry have a more balanced level of output value and employment structure. In the section of quantitative analysis, this paper used panel data from 31 provinces and cities and obtained GMM results, finding out that tertiary industry has the most dominant effects on economic development. Therefore, shifting focus to key state support and encouragement on the tertiary industry can help ensure high-quality economic growth and better serve the long-term " 321 " development pattern. Further research may also be conducted by building a more scientifically reasonable index system to evaluate the industrial structure, and acquiring more complete data and variables to explore the relationship between industry structure and economic growth.

\section{References}

1. "China GDP Annual Growth Rate | 1989-2021 Data | 2022-2023 Forecast ", Tradingeconomics.com , 2021. [Online].Available: https://tradingeconomics.com/china/gdp-growthannual. [Accessed: 25- Apr- 2021].

2. J. Zhao and J. Tang, "Industrial Structural Change and Economic Growth in China, 1987-2008", China \& World Economy, vol. 23, no. 2, pp. 1-21, 2015. Available: $10.1111 /$ cwe.12104.

3. J. Zhao and J. Tang, "Industrial structure change and economic growth: A China-Russia comparison ", China Economic Review, vol. 47, pp. 219-233, 2018. Available: 10.1016/j.chieco.2017.08.008.

4. S. Writer, "What Are Primary, Secondary and Tertiary Industries?", Reference.com, 2021. [Online]. Available:https://www.reference.com/worldview/primary-secondary-tertiary-industries694776c84d79b390. [Accessed: 25- Apr- 2021].

5. W. Corden, "Relationships between Macro-economic and Industrial Policies", The World Economy, vol. 3, no. 2, pp. 167-184, 1980. Available: $10.1111 /$ j.14679701.1980.tb00295.x.

6. D. Hung, J. Zhang and S. Mirza, Industrial Structure and Employment Structure Coordination In Viet Nam.
Journal of Economics and Sustainable Development, 2015.

7. J. Tan, X. Hu, R. Hassink and J. Ni, "Industrial structure or agency: What affects regional economic resilience? Evidence from resource-based cities in China", Cities, vol. 106, p. 102906, 2020. Available: 10.1016/j.cities.2020.102906.

8. M. Moffatt, "The Definition and Relevance of Panel Data in Economic Research", ThoughtCo, 2019. [Online].Available:

https://www.thoughtco.com/panel-data-definitionin-economic-research-1147034. [Accessed: 25- Apr2021].

9. C. Hsiao, "Panel Data Analysis - Advantages and Challenges", SSRN Electronic Journal, 2006. Available: 10.2139/ssrn.902657.

10. J. Fernando, "Gross Domestic Product (GDP)", Investopedia, 2021. [Online]. Available: https://www.investopedia.com/terms/g/gdp.asp. [Accessed: 25- Apr- 2021].

11. A. Luong, "Generalized Method of Moments and Generalized Estimating Functions Using Characteristic Function", Open Journal of Statistics, vol. 10, no. 03, pp. 581-599, 2020. Available: $10.4236 /$ ojs.2020.103035. 